\title{
Synthesis, Crystal Structure, and Thermal Properties of $\mathrm{CaSO}_{4} \cdot 2 \mathrm{H}_{2} \mathrm{O}$ Single Crystals
}

\author{
Takanori Fukami ${ }^{1}$, Shuta Tahara ${ }^{1}$, Keiko Nakasone $^{1}$, Chitoshi Yasuda ${ }^{1}$ \\ ${ }^{1}$ Department of Physics and Earth Sciences, Faculty of Science, University of the Ryukyus, Japan \\ Correspondence: Takanori Fukami, Department of Physics and Earth Sciences, Faculty of Science, University of \\ the Ryukyus, Okinawa 903-0213, Japan. Tel: 81-98-895-8509. E-mail: fukami@ sci.u-ryukyu.ac.jp
}

$\begin{array}{lc}\text { Received: April 7, } 2015 & \text { Accepted: May 8, } 2015 \quad \text { Online Published: July 6, } 2015 \\ \text { doi:10.5539/ijc.v7n2p12 } & \text { URL: http://dx.doi.org/10.5539/ijc.v7n2p12 }\end{array}$

\begin{abstract}
Single crystals were grown at room temperature from the precursors $\mathrm{CaCO}_{3}$ and $\mathrm{NH}_{2} \mathrm{SO}_{3} \mathrm{H}$ by a gel method using agar-agar gel as the medium of growth. Differential scanning calorimetry, thermogravimetric-differential thermal analysis, and X-ray diffraction measurements were performed on the single crystals. The crystal structure of the grown crystals was confirmed to be very similar to that of calcium sulfate dihydrate $\left(\mathrm{CaSO}_{4} \cdot 2 \mathrm{H}_{2} \mathrm{O}\right.$, gypsum). The temperature at which dehydration and evaporation of intercalated water molecules in the single crystal occurred was found to be $375.9 \mathrm{~K}$, which was very close to that in $\mathrm{CaSO}_{4} \cdot 2 \mathrm{H}_{2} \mathrm{O}$. From all these results, we identified the grown single crystals as $\mathrm{CaSO}_{4} \cdot 2 \mathrm{H}_{2} \mathrm{O}$. The weight loss owing to the thermal decomposition of anhydrous $\mathrm{CaSO}_{4}$ formed by the dehydration of the single gypsum crystals was found to occur at $\sim 1530 \mathrm{~K}$. This weight loss was probably caused by the evolution of $\mathrm{SO}_{3}$ gas by sublimation, and the chalky white substance left in the open vessel after decomposition was calcium oxide $(\mathrm{CaO})$.
\end{abstract}

Keywords: gypsum $\mathrm{CaSO}_{4} \cdot 2 \mathrm{H}_{2} \mathrm{O}$, gel method, crystal structure, thermal decomposition, DSC, TG-DTA, X-ray diffraction

\section{Introduction}

Gypsum is used as a generic name for several types of products with a chemical composition of calcium sulfate (Beceiro et al., 2012; Lou et al., 2011; Masuda \& Celiz, 2009; Pinheiro \& Camarini, 2015; Prasad et al., 2005; Saha et al., 2012; Sakae et al., 2007; Zhang et al., 1996). These compounds are classified into three types by the number of hydrogen present in the crystal; calcium sulfate dihydrate $\left(\mathrm{CaSO}_{4} \cdot 2 \mathrm{H}_{2} \mathrm{O}\right)$, calcium sulfate hemihydrate $\left(\mathrm{CaSO}_{4} \cdot 0.5 \mathrm{H}_{2} \mathrm{O}, \alpha\right.$ - or $\beta$-hemihydrate forms), and calcium sulfate $\left(\mathrm{CaSO}_{4}, \alpha\right.$ - or $\gamma$-anhydrite forms). The $\mathrm{CaSO}_{4} \cdot 2 \mathrm{H}_{2} \mathrm{O}$ gypsum is transformed to $\mathrm{CaSO}_{4} \cdot 0.5 \mathrm{H}_{2} \mathrm{O}$ and $\mathrm{CaSO}_{4}$ by the evaporation of water molecules during the calcination process. The calcined $\mathrm{CaSO}_{4} \cdot 0.5 \mathrm{H}_{2} \mathrm{O}$ and $\mathrm{CaSO}_{4}$ gypsums are converted to $\mathrm{CaSO}_{4} \cdot 2 \mathrm{H}_{2} \mathrm{O}$ in accordance with the hydration reaction, and the hydrated gypsum forms a hard solid mass. The general dehydration reactions are written as follows (Beceiro et al., 2012; Pinheiro \& Camarini, 2015; Prasad et al., 2005):

$$
\begin{gathered}
\mathrm{CaSO}_{4} \cdot 2 \mathrm{H}_{2} \mathrm{O} \rightarrow \mathrm{CaSO}_{4} \cdot 0.5 \mathrm{H}_{2} \mathrm{O}+1.5 \mathrm{H}_{2} \mathrm{O} \\
\mathrm{CaSO}_{4} \cdot 0.5 \mathrm{H}_{2} \mathrm{O} \rightarrow \mathrm{CaSO}_{4}+0.5 \mathrm{H}_{2} \mathrm{O} .
\end{gathered}
$$

Gypsum is mainly used in cement industry as a conditioning agent. The setting time of cement is controlled by the addition of gypsum to the clinker during the grinding process. The hydrated gypsums have many beneficial properties, such as heat and sound insulation, fire resistance, waterproof ability, etc (Pinheiro \& Camarini, 2015). Due to these magnificent properties, gypsums are being used in plaster, plaster boards, dental models, surgical casts, and paint fillers. Gypsum plaster is predominantly used in building construction for pastes, mortars, masonry blocks, ceiling boards, and decorative elements. Moreover, gypsum is used as a fertilizer to supplement calcium and as a ground material to improve alkaline soil.

The crystal structure of $\mathrm{CaSO}_{4} \cdot 2 \mathrm{H}_{2} \mathrm{O}$ was first determined from two-dimensional X-ray diffraction data using Fourier methods with $13.6 \% R$-factor for data (Wooster, 1936). Subsequently, structural studies were conducted using X-ray and neutron diffraction at room and low temperatures (Cole \& Lancucki, 1974; Comodi et al., 2008; Knight et al., 1999; Schofield et al., 1996). The structure of $\mathrm{CaSO}_{4} \cdot 2 \mathrm{H}_{2} \mathrm{O}$ at room temperature is monoclinic with the space group $C 2 / c$; the unit cell contains four molecules and has lattice parameters of $a=6.277(2) \AA$, 
$b=15.181(6) \AA, c=5.672(2) \AA$, and $\beta=114.11(2)^{\circ}$ (Comodi et al., 2008). Furthermore, the monoclinic structure with the space group $I 2 / a$ and unit cell parameters of $a=5.670(2) \AA, b=15.201(2) \AA, c=6.533(2) \AA$, and $\beta=118.36(4)^{\circ}$, has also been reported in several papers (Cole \& Lancucki, 1974; Knight et al., 1999; Schofield et al., 1996). The lattice parameters and atomic coordinates in the $C 2 / c$ structure are related to those in the $I 2 / a$ structure by a symmetry operation (Follner et al., 2002); thus, these two reported structures are identical. The structure of $\mathrm{CaSO}_{4} \cdot 2 \mathrm{H}_{2} \mathrm{O}$ consists of $\mathrm{SO}_{4}$ tetrahedra, $\mathrm{CaO}_{8}$ polyhedra, and weak hydrogen bonds between the nearest-neighbor oxygen atoms of $\mathrm{SO}_{4}$ tetrahedra and intercalated $\mathrm{H}_{2} \mathrm{O}$ molecules. Two of the oxygen atoms within the $\mathrm{CaO}_{8}$ polyhedra belong to $\mathrm{H}_{2} \mathrm{O}$ molecules, whereas the remaining six oxygen atoms belong to $\mathrm{SO}_{4}$ groups. Moreover, the structure is comprised of long zig-zag chains bonded by weak hydrogen bonds connecting neighbouring $\mathrm{SO}_{4}$ tetrahedra and $\mathrm{H}_{2} \mathrm{O}$ molecules (Cole \& Lancucki, 1974; Comodi et al., 2008).

The purpose of this paper is to report the synthesis of single crystals of $\mathrm{CaSO}_{4} \cdot 2 \mathrm{H}_{2} \mathrm{O}$ using gel method. The thermal properties of the grown crystals were studied using differential scanning calorimetry and thermogravimetric-differential thermal analysis. Moreover, the grown crystals were confirmed to be identical to gypsum $\mathrm{CaSO}_{4} \cdot 2 \mathrm{H}_{2} \mathrm{O}$ by thermal analyses and X-ray structure determination.

\section{Experimentals}

\subsection{Crystal Growth}

Single crystals of $\mathrm{CaSO}_{4} \cdot 2 \mathrm{H}_{2} \mathrm{O}$ were grown at room temperature by a slow diffusion method using agar-agar gel in U-shaped tubes. The U-tubes used as crystallizing vessels were open at both ends with an arm length of 180 $\mathrm{mm}$ and a diameter of $18 \mathrm{~mm}$. Agar-agar gels with a concentration of $\sim 1.5 \%$ were prepared by dissolving $2.9 \mathrm{~g}$ of agar-agar powder in $190 \mathrm{ml}$ of boiling distilled water. The agar-agar gel (about $35 \mathrm{ml}$ ) as the medium of growth was placed in the U-tubes and allowed to set and age for one day. An aqueous suspension $(10 \mathrm{ml})$ of 0.5 $\mathrm{M} \mathrm{CaCO}_{3}$ and an aqueous solution $(10 \mathrm{ml})$ of $1.5 \mathrm{M} \mathrm{NH}_{2} \mathrm{SO}_{3} \mathrm{H}$ were poured into the two limbs of the U-tube, respectively. $\mathrm{CaCO}_{3}$, which is insoluble in water, then precipitated on the surface of the agar-agar gel in the tube. The crystals were grown by the slow diffusion of ions from the $\mathrm{NH}_{2} \mathrm{SO}_{3} \mathrm{H}$ solution through the agar-agar gel into the vicinity of the surface precipitation of $\mathrm{CaCO}_{3}$. The yield of the grown crystal was about $35 \%$.

\subsection{X-ray Crystal Structure Determination}

The X-ray diffraction measurements were carried out by using a Rigaku Saturn CCD X-ray diffractometer with graphite monochromated Mo $K_{\alpha}$ radiation $(\lambda=0.71073 \AA$ A $)$. The diffraction data were collected at $298 \mathrm{~K}$ using an $\omega$ scan mode with a crystal-to-detector distance of $40 \mathrm{~mm}$, and processed using the CrystalClear software package. The sample was spherical in shape with a diameter of $0.30 \mathrm{~mm}$. The intensity data were corrected for Lorentz polarization and absorption effects. The structure was solved with direct methods using the SIR2008 program and refined on $F^{2}$ by full-matrix least-squares methods on $F^{2}$ using the SHELXL-2013 program in the WinGX package (Burla et al., 2007; Farrugia, 2012; Scheldrick, 2013).

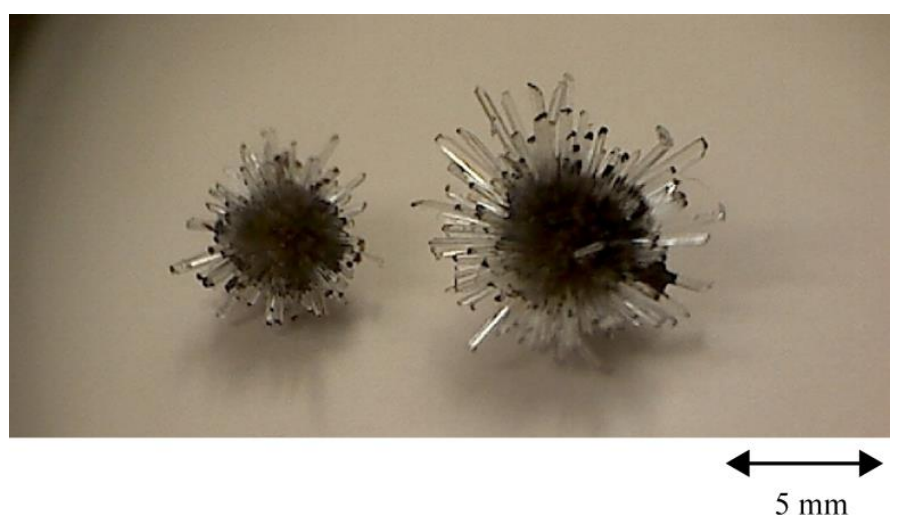

Figure 1. Photograph of gypsum $\mathrm{CaSO}_{4} \cdot 2 \mathrm{H}_{2} \mathrm{O}$ crystals grown by the gel method using agar-agar gel.

\section{3 Thermal Measurements}

Differential scanning calorimetry (DSC) and thermogravimetric-differential thermal analysis (TG-DTA) measurements were carried out in the temperature ranges of $105-520 \mathrm{~K}$ and $300-1600 \mathrm{~K}$, respectively, using DSC7020 and TG-DTA7300 systems from Seiko Instruments Inc. Aluminum open, aluminum hermetic, and alumina open pans were used as sample and reference pans for the DSC and TG-DTA measurements. Both single-crystal and fine powder (prepared from crushed single crystals) samples were used for the measurements. 
The sample amounts for the measurements varied between 0.74 and $4.45 \mathrm{mg}$, and the heating rates were 5 or 10 $\mathrm{K} /$ min under a dry $\mathrm{N}_{2}$ gas flow.

\section{Results and Discussion}

\subsection{Crystal Shape}

A typical photograph of two crystals grown by the gel method is shown in Fig. 1. The crystals are mainly composed of a roughly spherical aggregate crystal at the center with transparent elongated crystals grown from the aggregation center. The overall size of the large crystal, as shown at the right-hand side in Fig. 1, is about 8 $\mathrm{mm}$, and the sizes of the elongated crystals are usually less than about $0.5 \times 0.5 \times 4 \mathrm{~mm}$. The transparent elongated crystals grown from the center were used for X-ray diffraction and thermal analysis experiments.

Table 1. Crystal data, intensity collection and structure refinement parameters for $\mathrm{CaSO}_{4} \cdot 2 \mathrm{H}_{2} \mathrm{O}$ at room temperature.

\begin{tabular}{ll}
\hline Compound, $M_{\mathrm{r}}$ & $\mathrm{CaSO}_{4} \cdot 2 \mathrm{H}_{2} \mathrm{O}, 172.17$ \\
Crystal shape, color & Prism, colorless \\
Crystal system, space group & Monoclinic, $C 2 / c$ \\
Lattice constants & $a=6.2826(7) \AA, \quad, b=15.2177(11) \AA$, \\
& $c=5.6783(8) \AA, \beta=114.079(5)^{\mathrm{o}}$ \\
$V, Z$ & $495.64(10) \AA^{3}, 4$ \\
$D($ cal. $), \mu\left(\right.$ Mo $\left.K_{\alpha}\right), F(000)$ & $2.307 \mathrm{Mg} / \mathrm{m}^{3}, 1.630 \mathrm{~mm}^{-1}, 352$ \\
Sample shape, size in diameter & Sphere, $2 r=0.30 \mathrm{~mm}$ \\
$\theta$ range for data collection & $3.80-37.70^{\circ}$ \\
Index ranges & $-10 \leq h \leq 10,-25 \leq k \leq 25,-9 \leq l \leq 9$ \\
Reflections collected, unique & $6846,1291[R(\mathrm{int})=0.0477]$ \\
Completeness to $\theta_{\max }$ & $97.3 \%$ \\
Absorption correction type & $\mathrm{Spherical}$ \\
Transmission factor $T_{\min }-T_{\max }$ & $0.7431-0.7468$ \\
Data, parameter & $1033[I>2 \sigma(I)], 47$ \\
Final $R$ indices & $R_{1}=0.0245, w R_{2}=0.0690$ \\
$R$ indices (all data) & $R_{1}=0.0334, w R_{2}=0.0717$ \\
Weighting scheme & $w=1 /\left[\sigma^{2}\left(F_{\mathrm{o}}^{2}\right)+(0.0243 P)^{2}+0.0565 P\right]$ \\
& $P=\left(F_{\mathrm{o}}^{2}+2 F_{\mathrm{c}}^{2}\right) / 3$ \\
Goodness-of-fit on $F^{2}$ & 1.161 \\
Extinction coefficient & $0.000(3)$ \\
Largest diff. peak and hole & 0.427 and $-0.616 \mathrm{e} \AA^{-3}$ \\
\hline
\end{tabular}

\section{2 Crystal Structure}

The crystal structure of the prepared sample was determined at room temperature by X-ray diffraction. The lattice parameters calculated from all observed reflections indicated that the crystal belongs to the monoclinic system. The systematic extinctions in the observed reflections revealed that the possible space group of the sample is $C c$ or $C 2 / c$. Furthermore, the intensity statistics strongly indicated that the crystal belongs to a centrosymmetric group; thus, the space group of the sample was determined to be $C 2 / c$. A final $R$-factor of $2.45 \%$ was calculated for 1033 unique observed reflections. The lattice parameters and atomic coordinates calculated from the reflections of our sample are very similar to those reported for $\mathrm{CaSO}_{4} \cdot 2 \mathrm{H}_{2} \mathrm{O}$ in previous papers (Comodi et al., 2008; Wooster, 1936). When either one of the two $\mathrm{O}$ atoms $\left(\mathrm{O}(1)\right.$ and $\mathrm{O}(2)$ ) in the $\mathrm{SO}_{4}$ tetrahedron was substituted by an $\mathrm{N}$ atom, the $R$-factors were calculated to be about $4 \%$. Therefore, it is considered that the single crystals grown by the gel method do not contain $\mathrm{N}$ atoms from the starting precursor $\mathrm{NH}_{2} \mathrm{SO}_{3} \mathrm{H}$. The relevant crystal data and a summary of the intensity data collection and structure refinement parameters are given in Table 1. Figure 2 shows two views of the crystal structure along the (a) $c$-and (b) $a$-axes. The positional parameters in fractions of a unit cell and the thermal parameters are listed in Table 2. Selected bond lengths (in $\AA$ ) and angles (in degrees) are given in Table 3 . The hydrogen-bond geometry (in $\AA$ and degrees) is presented in Table 4.

The obtained structure consists of $\mathrm{SO}_{4}$ tetrahedra, $\mathrm{CaO}_{8}$ polyhedra, and weak hydrogen bonds formed between the $\mathrm{O}$ atoms of nearest-neighbor $\mathrm{SO}_{4}$ tetrahedra and intercalated $\mathrm{H}_{2} \mathrm{O}$ molecules. The two independent $\mathrm{S}-\mathrm{O}$ bond lengths in the $\mathrm{SO}_{4}$ tetrahedron are nearly equal at $\sim 1.474 \AA(1.4733(8)$ and $1.4752(8) \AA)$, and the $\mathrm{O}-\mathrm{S}-\mathrm{O}$ bond angles are in the range of 106.32(5)-111.35(7) ${ }^{\circ}$. Moreover, the four independent $\mathrm{Ca}-\mathrm{O}$ bond lengths in the $\mathrm{CaO}_{8}$ polyhedron are in the range of $2.3654(9)-2.5520(9) \AA$, and the weak $\mathrm{O}-\mathrm{H} \cdots \mathrm{O}$ hydrogen-bond lengths are 2.811(2) and 2.889(1) $\AA$. Neighboring $\mathrm{SO}_{4}$ tetrahedra are connected with each other through two bridging $\mathrm{H}_{2} \mathrm{O}$ molecules, as shown in Fig. 2(b). Moreover, two hydrogen-bonding networks on the $b c$-plane, which are topologically equivalent to each other, are formed with $\mathrm{SO}_{4}$ tetrahedra and $\mathrm{H}_{2} \mathrm{O}$ molecules and have zig-zag 
chains along the $c$-axis. As seen in Fig. 2(a), hollow tube shapes along the $c$-axis are composed of two $\mathrm{SO}_{4}$ tetrahedra and four $\mathrm{H}_{2} \mathrm{O}$ molecules with weak hydrogen bonds. The observed bond lengths and angles are very close to those previously reported for $\mathrm{CaSO}_{4} \cdot 2 \mathrm{H}_{2} \mathrm{O}$ (Cole \& Lancucki, 1974; Comodi et al., 2008; Knight et al., 1999; Schofield et al., 1996). The $\mathrm{H}-\mathrm{O}-\mathrm{H}$ angle of the $\mathrm{H}_{2} \mathrm{O}$ molecule in this study is $113(2)^{\circ}$, which is slightly larger than the value of $104.45^{\circ}$ in free water molecules and close to that of $107(1)^{\circ}$ reported in the previous paper (Cole \& Lancucki, 1974). The $\mathrm{H}-\mathrm{O}-\mathrm{H}$ angle depends strongly on the orientation of the hydrogen bond. Therefore, the difference between the angles of free water and intercalated $\mathrm{H}_{2} \mathrm{O}$ molecules in the single crystal is caused by the positional relation between the two $\mathrm{O}$ atoms involved in the $\mathrm{O}-\mathrm{H} \cdots \mathrm{O}$ hydrogen bond. These experimental results indicate that the crystal structure of the single crystal grown by the gel method is identical with that of $\mathrm{CaSO}_{4} \cdot 2 \mathrm{H}_{2} \mathrm{O}$ reported in previous papers (Cole \& Lancucki, 1974; Comodi et al., 2008; Knight et al., 1999; Schofield et al., 1996; Wooster, 1936).

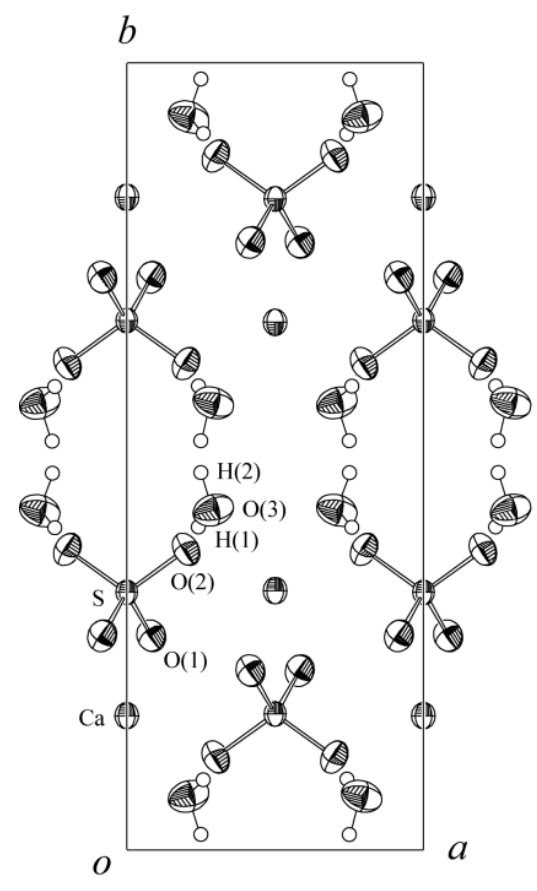

(a)

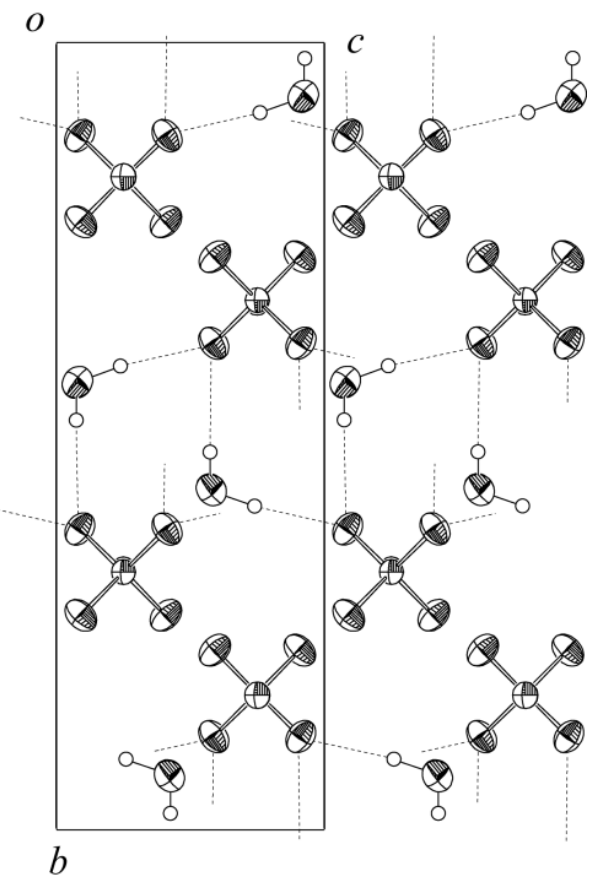

(b)

Figure 2. Perspective views along the (a) $c$ - and (b) $a$-axes of $\mathrm{CaSO}_{4} \cdot 2 \mathrm{H}_{2} \mathrm{O}$ at room temperature with $80 \%$ probability-displacement thermal ellipsoids. The (b) structure shows $\mathrm{SO}_{4}$ tetrahedra and $\mathrm{H}_{2} \mathrm{O}$ molecules along the $a$-axis with $0.5 \leq x \leq 1.0$. The dashed short lines show $\mathrm{O}-\mathrm{H} \cdots \mathrm{O}$ hydrogen bonds.

Table 2. Atomic coordinates and thermal parameters $\left(\times 10^{4} \AA^{2}\right)$ with standard deviations in parentheses for $\mathrm{CaSO}_{4} \cdot 2 \mathrm{H}_{2} \mathrm{O}$ crystal at room temperature. The anisotropic thermal parameters are defined as $\exp \left[-2 \pi^{2}\left(U_{11} a^{* 2} h^{2}\right.\right.$ $\left.\left.+U_{22} b^{* 2} k^{2}+U_{33} c^{* 2} l^{2}+2 U_{23} b^{*} c^{*} k l+2 U_{13} a^{*} c^{*} h l+2 U_{12} a^{*} b^{*} h k\right)\right]$. The isotropic thermal parameters $\left(\AA^{2}\right)$ for $\mathrm{H}$ atoms are listed under $U_{11}$.

\begin{tabular}{llllllllll}
\hline Atom & $x$ & $y$ & $z$ & $U_{11}$ & $U_{22}$ & $U_{33}$ & $U_{23}$ & $U_{13}$ & $U_{12}$ \\
\hline $\mathrm{Ca}$ & 0 & $0.17051(2)$ & 0.25 & $114(1)$ & $144(2)$ & $129(1)$ & 0 & $61(1)$ & 0 \\
$\mathrm{~S}$ & 0 & $0.32727(2)$ & 0.75 & $97(2)$ & $126(2)$ & $117(2)$ & 0 & $59(1)$ & 0 \\
$\mathrm{O}(1)$ & $0.0829(2)$ & $0.27217(6)$ & $0.5912(2)$ & $170(4)$ & $205(4)$ & $201(4)$ & $-64(3)$ & $117(3)$ & $-17(3)$ \\
$\mathrm{O}(2)$ & $0.1999(2)$ & $0.38193(6)$ & $0.9127(2)$ & $153(4)$ & $211(4)$ & $182(4)$ & $-53(3)$ & $73(3)$ & $-48(3)$ \\
$\mathrm{O}(3)$ & $0.2917(2)$ & $0.43181(7)$ & $0.4216(2)$ & $331(6)$ & $207(5)$ & $186(5)$ & $26(4)$ & $74(4)$ & $48(4)$ \\
$\mathrm{H}(1)$ & $0.242(3)$ & $0.411(1)$ & $0.260(4)$ & $0.039(7)$ & & & & & \\
$\mathrm{H}(2)$ & $0.250(4)$ & $0.480(2)$ & $0.427(4)$ & $0.055(7)$ & & & & & \\
\hline
\end{tabular}


Table 3. Selected interatomic distances (in $\AA$ ) and angles (in degrees) for $\mathrm{CaSO}_{4} \cdot 2 \mathrm{H}_{2} \mathrm{O}$ crystal at room temperature.

\begin{tabular}{llll}
\hline $\mathrm{Ca}-\mathrm{Ca}^{(\mathrm{a})}$ & $4.0625(5)$ & $\mathrm{Ca}-\mathrm{O}(1)[\times 2]$ & $2.3654(9)$ \\
$\mathrm{Ca}-\mathrm{O}(1)^{(\mathrm{b})}[\times 2]$ & $2.5520(9)$ & $\mathrm{Ca}-\mathrm{O}(2)^{(\mathrm{b})}[\times 2]$ & $2.5430(9)$ \\
$\mathrm{Ca}-\mathrm{O}(3)^{(\mathrm{b})}[\times 2]$ & $2.371(1)$ & $\mathrm{S}-\mathrm{O}(1)$ & $1.4733(8)$ \\
$\mathrm{S}-\mathrm{O}(2)$ & $1.4752(8)$ & $\mathrm{O}(1)-\mathrm{O}(2)$ & $2.360(1)$ \\
$\mathrm{O}(1)-\mathrm{O}(1)^{(\mathrm{c})}$ & $2.423(2)$ & $\mathrm{O}(2)-\mathrm{O}(2)^{(\mathrm{c})}$ & $2.437(2)$ \\
$\mathrm{O}(1)-\mathrm{S}-\mathrm{O}(1)^{(\mathrm{c})}$ & $110.62(7)$ & $\mathrm{O}(1)-\mathrm{S}-\mathrm{O}(2)$ & $106.32(5)$ \\
$\mathrm{O}(1)-\mathrm{S}-\mathrm{O}(2)^{(\mathrm{c})}$ & $111.15(5)$ & $\mathrm{O}(2)-\mathrm{S}-\mathrm{O}(2)^{(\mathrm{c})}$ & $111.35(7)$ \\
$\mathrm{H}(1)-\mathrm{O}(3)-\mathrm{H}(2)$ & $113(2)$ & & \\
\hline
\end{tabular}

Symmetry codes: (a) $-x+1 / 2,-y+1 / 2,-z+1$, (b) $x-1 / 2,-y+1 / 2, z-1 / 2$, (c) $-x, y,-z+3 / 2$.

Table 4. Hydrogen bond distances (in $\AA$ ) and angles (in degrees) for $\mathrm{CaSO}_{4} \cdot 2 \mathrm{H}_{2} \mathrm{O}$ crystal at room temperature.

\begin{tabular}{lllll}
\hline & $\mathrm{O}-\mathrm{H}$ & $\mathrm{H} \cdots \mathrm{O}$ & $\mathrm{O} \cdots \mathrm{O}$ & $<\mathrm{O}-\mathrm{H} \cdots \mathrm{O}$ \\
\hline $\mathrm{O}(3)-\mathrm{H}(1) \cdots \mathrm{O}(2)^{(\mathrm{a})}$ & $0.90(2)$ & $1.93(2)$ & $2.811(2)$ & $166(2)$ \\
$\mathrm{O}(3)-\mathrm{H}(2) \cdots \mathrm{O}(2)^{(\mathrm{b})}$ & $0.78(2)$ & $2.12(2)$ & $2.889(1)$ & $167(2)$ \\
\hline
\end{tabular}

Symmetry codes: (a) $x, y, z-1$, (b) $x,-y+1, z-1 / 2$.

\subsection{DSC and TG-DTA Measurements}

Some of the transparent elongated single crystals that extended from the roughly spherical central aggregate crystal, as shown in Fig. 1, were reduced to a fine powder. The powder was divided into three parts for use in thermal measurements. Two powder samples were used for DSC measurements, and the remaining one for TG-DTA measurements. Figure 3(a) shows the DSC heating curve for a single crystal sample, and figures 3(b) and 3(c) show the heating curves for powder samples. Aluminum open pans (as both sample and reference pans) were used in the measurements of the (a) and (b) curves, and aluminum hermetic pans were used for the (c) curve. No pan cover over the open pans was used in the measurements of the (a) and (b) curves. The heating rate for all the measurements was $5 \mathrm{~K} / \mathrm{min}$ under a dry $\mathrm{N}_{2}$ gas flow of $40 \mathrm{ml} / \mathrm{min}$. There are significant differences in the peak shape and position among the curves in Fig. 3. The measurement conditions for the (a), (b), and (c) curves are completely the same, except for the sample form (single crystal or powder) and vessel type (open or hermetic pan). Therefore, the differences between the (a) and (b) curves, and between the (b) and (c) curves are caused by the differences in the sample and vessel type, respectively.

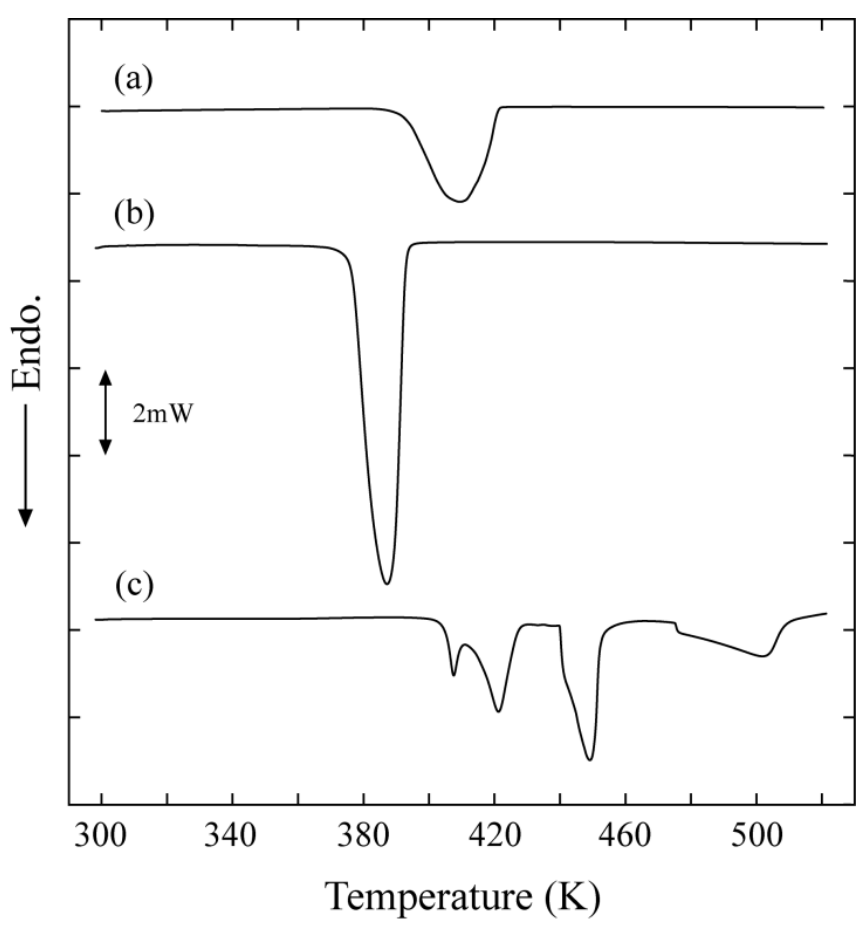

Figure 3. DSC heating curves for $\mathrm{CaSO}_{4} \cdot 2 \mathrm{H}_{2} \mathrm{O}$ crystals in open [(a) and (b)] and hermetic [(c)] pans. The sample in the (a) curve was a single crystal, and those in the (b) and (c) curves were a fine powder. The sample weights for (a), (b), and (c) were $0.76,1.80$, and $1.82 \mathrm{mg}$, respectively. The heating rates were $5 \mathrm{~K} / \mathrm{min}$ under a dry $\mathrm{N}_{2}$ flux of $40 \mathrm{ml} / \mathrm{min}$. 
A small or large endothermic peak is clearly seen in the (a) and (b) DSC curves at 409.5 and $387.1 \mathrm{~K}$, respectively. The onset temperatures of the small and large peaks respectively were determined to be 392.6 and $375.9 \mathrm{~K}$. The onset temperature of the powder sample $(375.9 \mathrm{~K}$, (b) curve) is very close to the boiling point of water $(373 \mathrm{~K})$. Moreover, the obtained peak temperatures are close to that of $\mathrm{CaSO}_{4} \cdot 2 \mathrm{H}_{2} \mathrm{O}(\sim 400 \mathrm{~K})$ reported in previous papers (Beceiro et al., 2012; Lou et al., 2011; Sakae et al., 2007). However, there is a significant difference between the observed curves and the previously reported ones, where, in addition to the large endothermic peak around $400 \mathrm{~K}$ in the DSC curve, there is a small peak around $420 \mathrm{~K}$ (Beceiro et al., 2012; Sakae et al., 2007). On the other hand, the observed (a) and (b) curves for the single crystal and powder samples clearly exhibit a single sharp peak, and no shoulder or second peak is observed.

The onset and peak temperatures for the powder sample ((b) curve) are lower by 17 and $22 \mathrm{~K}$ than those for the single crystal ((a) curve), respectively. The temperature difference between the onset and peak temperatures in the powder sample is smaller than that in the single crystal (11 and $17 \mathrm{~K}$, respectively). Generally, it is believed that a clear peak in a DSC curve is attributed to the change of exchange energy at phase transition in almost all cases. The start and end temperatures of the phase transition correspond to the onset and peak temperatures in the DSC curve, respectively. Thus, these results indicate that the transition temperature in the powder sample is shifted toward lower temperatures compared with that in the single crystal, and the temperature range of the transition for the powder sample is also slightly narrower than that for the single crystal. Moreover, no significant endothermic or exothermic peaks were observed in the DSC curve of the single crystal at low temperatures in the range of $105-320 \mathrm{~K}$. These results indicate that there is no phase transition in the temperature range between 105 and $375.9 \mathrm{~K}$ in the single crystals grown by the gel method.

Table 5 Peak temperatures, onset temperatures (transition temperatures), transition enthalpies $\Delta H$, and entropies $\Delta S$ for $\mathrm{CaSO}_{4} \cdot 2 \mathrm{H}_{2} \mathrm{O}$ crystals obtained from DSC [(a), (b), and (c) in Fig. 2], DTA, and DTG curves.

\begin{tabular}{|c|c|c|c|c|c|c|c|c|}
\hline \multirow[t]{4}{*}{ DSC [(a) curve] } & Peak Temp. (K) & 409.5 & & & & & & \\
\hline & Onset Temp. (K) & 392.6 & & & & & & \\
\hline & $\Delta H\left(\mathrm{~kJ} \mathrm{~mol}^{-1}\right)$ & 107.6 & & & & & & \\
\hline & $\Delta S / R$ & 33.0 & & & & & & \\
\hline \multirow[t]{4}{*}{ DSC [(b) curve] } & Peak Temp. (K) & 387.1 & & & & & & \\
\hline & Onset Temp. (K) & 375.9 & & & & & & \\
\hline & $\Delta H\left(\mathrm{~kJ} \mathrm{~mol}^{-1}\right)$ & 96.6 & & & & & & \\
\hline & $\Delta S / R$ & 30.9 & & & & & & \\
\hline \multirow[t]{4}{*}{ DSC [(c) curve $]$} & Peak Temp. (K) & & 407.5 & 421.2 & 449.1 & 501.8 & & \\
\hline & Onset Temp. (K) & & 404.4 & 411.3 & 439.7 & 475.0 & & \\
\hline & $\Delta H\left(\mathrm{~kJ} \mathrm{~mol}^{-1}\right)$ & & 6.5 & 19.6 & 29.4 & 20.7 & & \\
\hline & $\Delta S / R$ & & 1.9 & 5.7 & 8.1 & 5.2 & & \\
\hline \multirow[t]{2}{*}{ DTA } & Peak Temp. (K) & 392.4 & & & & & 1495.1 & 1529.6 \\
\hline & Onset Temp. (K) & 376.2 & & & & & 1491.4 & 1458.1 \\
\hline \multirow[t]{2}{*}{ DTG } & Peak Temp. (K) & 388.6 & & & & & & 1524.8 \\
\hline & Onset Temp. (K) & 374.0 & & & & & & 1327.3 \\
\hline
\end{tabular}

Gas constant $R=8.314 \mathrm{JK}^{-1} \mathrm{~mol}^{-1}$

The transition enthalpies $\Delta H$ (entropies $\Delta S$ ) determined from the small and large endothermic peaks of the single crystal and powder samples respectively are $107.6(33.0 R)$ and $96.6 \mathrm{~kJ} \mathrm{~mol}^{-1}(30.9 R)$, where $R$ is the gas constant $\left(8.314 \mathrm{JK}^{-1} \mathrm{~mol}^{-1}\right)$. The obtained enthalpy values are close to that reported previously $\left(93.6 \mathrm{~kJ} \mathrm{~mol}^{-1}\right)$ (Beceiro et al., 2012).

As seen in the (c) curve of Fig. 3, the endothermic peak at $387.1 \mathrm{~K}$ observed in the (b) curve disappears completely and four new endothermic peaks appear at temperatures above $400 \mathrm{~K}$. As mentioned above, the differences in peak shape and position between the (b) and (c) curves are caused by the difference between the open and hermetic pans. The observed (c) curve is very similar to that previously reported at temperatures above $420 \mathrm{~K}$ and at pressures above 50 bar when the vessel developed a pin-hole leak (Beceiro et al., 2012). The peak temperatures of the four peaks were observed at 407.5, 421.2, 449.1, and $501.8 \mathrm{~K}$, and the transition enthalpies $\Delta H$ (entropies $\Delta S$ ) associated with these peaks were determined to be $6.5(1.9 R), 19.6(5.7 R), 29.4(8.1 R)$, and $20.7 \mathrm{~kJ} \mathrm{~mol}^{-1}(5.2 R)$. The values of $\Delta H(\Delta S)$ at 407.5 and $421.2 \mathrm{~K}$ were determined by separating the overlapped endothermic peaks. The total value of $76.2 \mathrm{~kJ} \mathrm{~mol}^{-1}(20.9 R)$ obtained by summing the individual values of $\Delta H$ $(\Delta S)$ from the (c) curve is smaller than that $\left(96.6 \mathrm{~kJ} \mathrm{~mol}^{-1}(30.9 R)\right.$ ) obtained from the (b) curve. The $\mathrm{H}_{2} \mathrm{O}$ molecules evaporated from the sample in the (b) curve diffuse into the air since open pans were used, but those in the sample of the (c) curve stay in the hermetic vessel. The pressure in the hermetic vessel is increased by the increase in temperature and by the increase in vapor pressure owing to the evaporation of the $\mathrm{H}_{2} \mathrm{O}$ molecules. Therefore, it is considered from these results that the endothermic peak shape and the number of peaks in the (c) 
curve are affected by the pressure which depends on the temperature and/or the vapor pressure in the hermetic vessel. Moreover, the smaller $\Delta H(\Delta S)$ values obtained with the hermetic pans than with the open pans may be caused by the difference in the ability of the $\mathrm{H}_{2} \mathrm{O}$ molecules to diffuse out of the vessel. Table 5 shows the peak temperatures, onset temperatures (transition temperatures), transition enthalpies $\Delta H$ and entropies $\Delta S$ determined from the DSC curves for the single crystal and powder samples.

Figure 4 shows the TG, differential TG (DTG), and DTA thermal analysis curves for the powder sample in the temperature range of 300-1600 K. The powder sample was prepared from single crystals as described above, and the sample quality is the same as those used in the DSC measurements. Alumina open pans (as sample and reference pans) with no pan cover were used as the measuring vessels. The heating rate was $10 \mathrm{~K} / \mathrm{min}$ under a dry $\mathrm{N}_{2}$ gas flow of $300 \mathrm{ml} / \mathrm{min}$. The DTA curve exhibited a single endothermic peak around $400 \mathrm{~K}$, which is very similar to that in the DSC curve. The onset and peak temperatures in the DTA curve were observed at 376.2 and $392.4 \mathrm{~K}$, respectively. These temperatures are very close to those (375.9 and 387.1 K) observed for the (b) DSC curve of the powder sample. Slight differences between these temperatures are probably caused by the difference in heating rate between the measurements. The weight loss in the TG curve was also observed near the DTA peak temperature of $392.4 \mathrm{~K}$. The temperature dependence of this weight loss shows a smooth decrease with increasing temperature, and the DTG curve, which is the first derivative of TG curve, exhibits a single peak, as shown in Fig. 4. Large and small endothermic peaks in DSC and DTA curves were previously reported to be observed around 400 and $420 \mathrm{~K}$, respectively, at atmosphere pressure (Beceiro et al., 2012; Lou et al., 2011; Sakae et al., 2007; Zhang et al., 1996). These peaks correspond to the two dehydration reactions described in the Introduction. $\mathrm{CaSO}_{4} \cdot 2 \mathrm{H}_{2} \mathrm{O}$ single crystals or powders prepared by grinding the single crystals were not used for the measurements in the previous studies (Beceiro et al., 2012; Lou et al., 2011; Sakae et al., 2007; Zhang et al., 1996). In the present study, both the DSC and DTA curves show only a single endothermic peak around $390 \mathrm{~K}$, and the weight loss in the TG curve around this temperature shows a smooth decrease with increasing temperature, similarly to that previously reported (Carbone et al., 2008; Lou et al., 2011; Sarma et al., 1998). Moreover, the DTG curve in the present study also shows a single peak. Thus, these results indicate that the dehydration takes place in a single-step reaction at $375.9 \mathrm{~K}$. A major difference between the present study and the previous studies is the difference in sample quality (single crystals and gypsum reagent powder, respectively). Thus, we suggest that the existence of a small endothermic peak around $420 \mathrm{~K}$ in the DSC and DTA curves in the previous studies is probably caused by poor sample quality. In the analysis of the crystal structure above, the two $\mathrm{H}_{2} \mathrm{O}$ molecules in the single crystal were found to be crystallographically equivalent, as the two molecules are related to each other by a crystallographic symmetry operation, i.e., there is absolutely no difference in physical properties of these two molecules. Therefore, it is consistent with the crystallographic results that the dehydration of the two $\mathrm{H}_{2} \mathrm{O}$ molecules takes place in the single-step reaction at $375.9 \mathrm{~K}$.

The weight loss around $392.4 \mathrm{~K}$ in the TG curve was determined to be $19.7 \%$ in the temperature range from 365 to $445 \mathrm{~K}$. The theoretical weight loss caused by the evaporation of $\mathrm{H}_{2} \mathrm{O}$ in $\mathrm{CaSO}_{4} \cdot 2 \mathrm{H}_{2} \mathrm{O}$ is calculated to be $20.9 \%$ [ $=2 \times 18.02 / 172.17]$, and is very close to the experimental weight loss. Thus, the endothermic peak around $390 \mathrm{~K}$ in both the DSC and DTA curves corresponds to the evaporation of the $\mathrm{H}_{2} \mathrm{O}$ molecules in the crystal as mentioned above, and then as a result, $\mathrm{CaSO}_{4}$ is produced by further heating above $445 \mathrm{~K}$. All data obtained from the X-ray and thermal (DSC and TG-DTA) measurements are very consistent with the physical properties of gypsum $\mathrm{CaSO}_{4} \cdot 2 \mathrm{H}_{2} \mathrm{O}$ crystals. Therefore, the single crystals grown by the gel method are concluded to be $\mathrm{CaSO}_{4} \cdot 2 \mathrm{H}_{2} \mathrm{O}$.

Large peaks in the DTA and DTG curves are clearly seen at very high temperatures of 1529.6 and $1524.8 \mathrm{~K}$, respectively (Fig. 4). The weight loss in the TG curve was observed around the DTA peak temperature of 1529.6 $\mathrm{K}$, and was determined to be $44.2 \%$ in the temperature range from 1350 to $1575 \mathrm{~K}$. Assuming that the weight loss is caused by the evaporation of $\mathrm{SO}_{3}$ decomposed from $\mathrm{CaSO}_{4}$, the theoretical weight loss is then calculated to be $46.5 \%$ [ $=80.06 / 172.17]$. The calculated value is very close to the experimental weight loss of $44.2 \%$. Therefore, this weight loss around $1530 \mathrm{~K}$ is consistent with the evolution of $\mathrm{SO}_{3}$ gas by the sublimation of solid $\mathrm{SO}_{3}$. The thermal dehydration and decomposition reactions of the $\mathrm{CaSO}_{4} \cdot 2 \mathrm{H}_{2} \mathrm{O}$ single crystals in this present study are described as follows:

$$
\begin{gathered}
\mathrm{CaSO}_{4} \cdot 2 \mathrm{H}_{2} \mathrm{O} \rightarrow \mathrm{CaSO}_{4}+2 \mathrm{H}_{2} \mathrm{O} \\
\mathrm{CaSO}_{4} \rightarrow \mathrm{CaO}+\mathrm{SO}_{3} .
\end{gathered}
$$

After these measurements, a chalky white substance was left in the open vessel. This white substance is suggested to be calcium oxide $\mathrm{CaO}$ that is formed from $\mathrm{CaSO}_{4}$ following the sublimation of $\mathrm{SO}_{3}$ around $1530 \mathrm{~K}$. 


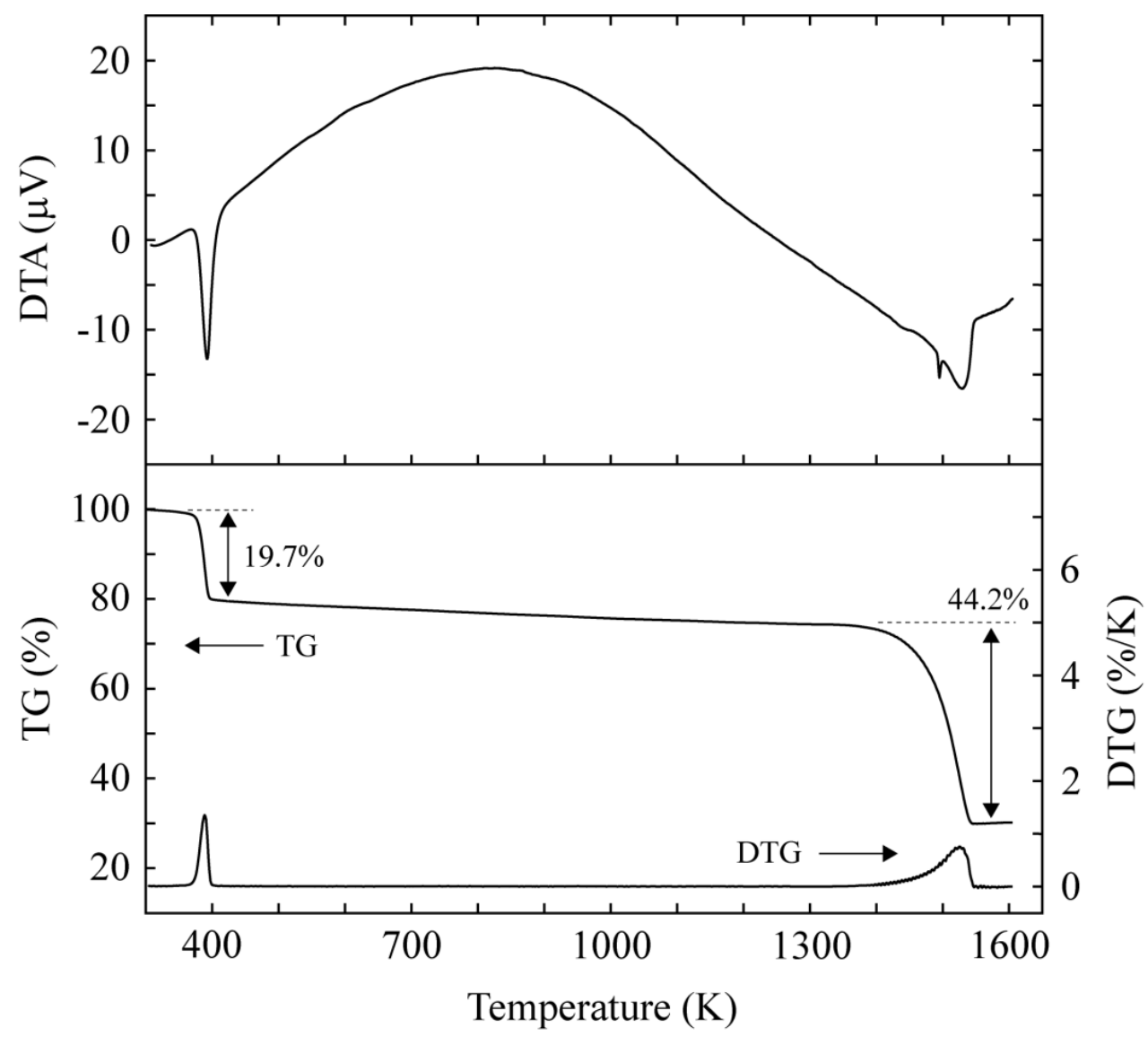

Figure 4. TG, DTG, and DTA thermograms of $\mathrm{CaSO}_{4} \cdot 2 \mathrm{H}_{2} \mathrm{O}$ crystal on heating. Sample weight (powder) was $1.67 \mathrm{mg}$, and the heating rate was $10 \mathrm{~K} / \mathrm{min}$ under a dry $\mathrm{N}_{2}$ flux of $300 \mathrm{ml} / \mathrm{min}$.

\section{Conclusion}

Single crystals were grown at ambient temperature from the precursors $\mathrm{CaCO}_{3}$ and $\mathrm{NH}_{2} \mathrm{SO}_{3} \mathrm{H}$ by the gel method using agar-agar gel as the medium of growth. The thermal properties and crystal structure on the single crystals were studied by DSC, TG-DTA, and X-ray diffraction measurements. The crystal structure of the crystal was determined at room temperature to be monoclinic with the space group $C 2 / c$ by means of single-crystal $\mathrm{X}$-ray diffraction, and was confirmed to be very similar to that of gypsum $\mathrm{CaSO}_{4} \cdot 2 \mathrm{H}_{2} \mathrm{O}$ crystal reported in previous papers. The results of DSC and TG-DTA analyses indicated that the dehydration and evaporation of water molecules intercalated in the single crystal take place at $375.9 \mathrm{~K}$ in a single-step reaction, and are also similar to those of gypsum $\mathrm{CaSO}_{4} \cdot 2 \mathrm{H}_{2} \mathrm{O}$ in previous studies except the dehydration is a two-step reaction. We concluded from these results that the grown crystals are identical with gypsum $\mathrm{CaSO}_{4} \cdot 2 \mathrm{H}_{2} \mathrm{O}$ crystal, and $\mathrm{CaSO}_{4} \cdot 2 \mathrm{H}_{2} \mathrm{O}$ single crystals can be grown from the precursors $\mathrm{CaCO}_{3}$ and $\mathrm{NH}_{2} \mathrm{SO}_{3} \mathrm{H}$ by the gel method. Moreover, the thermal decomposition of anhydrous $\mathrm{CaSO}_{4}$ formed by dehydration of $\mathrm{CaSO}_{4} \cdot 2 \mathrm{H}_{2} \mathrm{O}$ was found to occur around $1530 \mathrm{~K}$, and the weight loss owing to the decomposition was suggested to be caused by the evolution of $\mathrm{SO}_{3}$ gas. The chalky white substance left in the open vessel after the decomposition of $\mathrm{CaSO}_{4}$ was consistent with $\mathrm{CaO}$.

\section{References}

Beceiro ,J. L., Fernández, C. G., Saavedra, J. T., Barreiro, S. G., \& Artiaga, R. (2012). Study of gypsum by PDSC. J. Therm. Anal. Calorim, 109(3), 1177-1183. http://dx.doi.org/10.1007/s10973-012-2335-1

Burla, M. C., Caliandro, R., Camalli, M., Carrozzini, B., Cascarano, G. L., Caro, L. D., Giacovazzo, C., Polidori, G., Siliqi, D., \& Spagna, R. (2007). IL MILIONE: a suite of computer programs for crystal structure solution of proteins. J. Appl. Crystallogr, 40(3), 609-613. http://dx.doi.org/10.1107/S0021889807010941

Carbone, M., Ballirano, P., \& Caminiti, R. (2008). Kinetics of gypsum dehydration at reduced pressure: an energy dispersive X-ray diffraction study. Eur. J. Mineral, 20(4), 621-627. http://dx.doi.org/10.1127/0935-1221/2008/0020-1826 
Cole, W. F., \& Lancucki, C. J. (1974). A refinement of the crystal structure of gypsum $\mathrm{CaSO}_{4} \cdot 2 \mathrm{H}_{2} \mathrm{O}$. Acta Crystallogr, B30(4), 921-929. http://dx.doi.org/10.1107/S0567740874004055

Comodi, P., Nazzareni, S., Zanazzi, P. F., \& Speziale, S. (2008). High-pressure behavior of gypsum: A single-crystal X-ray study. Am. Mineral, 93(10), 1530-1537. http://dx.doi.org/10.2138/am.2008.2917

Farrugia, L. J. (2012). WinGX and ORTEP for Windows: an update. J. Appl. Crystallogr, 45(4), 849-854. http://dx.doi.org/10.1107/S0021889812029111

Follner, S., Wolter, A., Helming, K., Silber, C., Bartels, H., \& Follner, H. (2002). On the real structure of gypsum crystals. Cryst. Res. Technol., $207-218$. http://dx.doi.org/10.1002/1521-4079(200202)37:2/3<207::AID-CRAT207>3.0.CO;2-L

Knight, K. S., Stretton, I. C., \& Schofield, P. F. (1999). Temperature evolution between $50 \mathrm{~K}$ and $320 \mathrm{~K}$ of the thermal expansion tensor of gypsum derived from neutron powder diffraction data. Phys. Chem. Miner. 26(6), 477-483. http://dx.doi.org/10.1007/s002690050210

Lou, W., Guan, B., \& Wu, Z. (2011). Dehydration behavior of FGD gypsum by simultaneous. TG and DSC analysis. J. Therm. Anal. Calorim., 104(2), 661-669. http://dx.doi.org/10.1007/s10973-010-1100-6

Masuda, Y., \& Celiz, L. L. (2009). Technical know-how in thermal analysis measurement - Thermal analysis $\begin{array}{lllll}\text { under water vapor } \quad \text { atmosphere- } & \text { Rigaku } \quad J ., & 25(1), & 15-18 .\end{array}$ http://www.rigaku.com/downloads/journal/RJ26-2/RJ26-2_24-28.pdf

Pinheiro, S. M. M., \& Camarini, G. (2015). Characteristics of gypsum recycling in different cycles. Int. J. Eng. Technol., 7(3), 215-218. http://dx.doi.org/10.7763/IJET.2015.V7.794

Prasad, P. S. R., Chaitanya, V. K., Prasad, K. S., \& Rao, D. N. (2005). Direct formation of the $\gamma-\mathrm{CaSO}_{4}$ phase in dehydration process of gypsum: In situ FTIR study. Am. Mineral., 90(4), 672-678. http://dx.doi.org/10.2138/am.2005.1742

Saha, A., Lee, J., Pancera, S. M., Bräeu, M. F., Kempter ,A., Tripathi, A., \& Bose, A. (2012). New insights into the transformation of calcium sulfate hemihydrate to gypsum using time-resolved cryogenic transmission electron microscopy. Langmuir, 28(7), 11182-1118. http://dx.doi.org/10.1021/la3024474

Sakae, T., Sato, Y., Numata, Y., Suwa, T., Hayakawa, T., Suzuki, K., Kuwada, T., Hayakawa, K., Hayakawa, Y., Tanaka, T., \& Sato, I. (2007). Thermal ablation of FEL irradiation using gypsum as an indicator. Lasers Med. Sci., 22(1), 15-20. http://dx.doi.org/10.1007/s10103-006-0414-x

Sarma, L. P., Prasad, P. S. R., \& Ravikumar, N. (1998). Raman spectroscopic study of phase transitions in natural $\begin{array}{lllll}\text { gypsum. } & \text { J. Raman } & \text { Spectrosc., } & \text { 85(9), }\end{array}$ http://dx.doi.org/10.1002/(SICI)1097-4555(199809)29:9<851::AID-JRS313>3.0.CO;2-S

Scheldrick, G. M. (2013). SHELXL-2013, Program for Crystal Structure Refinement (University of Göttingen, Germany). Retrieved from http://shelx.uni-ac.gwdg.de/SHELX/

Schofield, P. F., Knight, K. S., \& Stretton, I. C. (1996). Thermal expansion of gypsum investigated by neutron powder diffraction. Am. Mineral., 81(7-8), 847-851. http://rruff.info/doclib/am/vol81/AM81_847.pdf

Wooster, W. A. (1936). On the crystal structure of gypsum, $\mathrm{CaSO}_{4} \cdot 2 \mathrm{H}_{2} \mathrm{O}$. Z. Kristallogr., 94(1), 375-396. http://dx.doi.org/10.1524/zkri.1936.94.1.375

Zhang, Q., Kasai, E., \& Saito, F. (1996). Mechanochemical changes in gypsum when dry ground with hydrated minerals. Powder Technol., 87(1), 67-71. http://dx.doi.org/10.1016/0032-5910(95)03069-7

\section{Copyrights}

Copyright for this article is retained by the author(s), with first publication rights granted to the journal.

This is an open-access article distributed under the terms and conditions of the Creative Commons Attribution license (http://creativecommons.org/licenses/by/3.0/). 